\title{
3 Research Suare \\ Investigating the Development of Inhibitory Control in Early Childhood using the Tablet-based TapTap Task
}

Muriel Marisa Katharina Bruchhage ( $\nabla$ muriel.bruchhage@kcl.ac.uk)

Brown University Warren Alpert Medical School https://orcid.org/0000-0001-9637-0951

Viren D'Sa

Brown University Warren Alpert Medical School

John Rogers

Rhode Island Hospital

Nora Schneider

Nestle Research Center

Sean C L Deoni

Brown University Warren Alpert Medical School

\section{Research Article}

Keywords: functional connectivity, MRI, executive function, inhibitory control, frontal lobe

Posted Date: February 25th, 2021

DOl: https://doi.org/10.21203/rs.3.rs-159267/v1

License: (c) (i) This work is licensed under a Creative Commons Attribution 4.0 International License. Read Full License 


\section{Abstract}

The development of inhibitory control is an early construct of executive function (EF) and a key milestone of neurocognitive maturation. However, while its functional connectivity $(\mathrm{fc})$ patterns have been welldefined in adults, its developmental trajectory in early childhood remains poorly understood. Using tabletbased EF tasks, we assessed inhibitory control in typically developing children between 2 to 6 years of age. Overall successful inhibition and improvement during competitive and non-competitive inhibition displayed converging patterns of $\mathrm{fc}$. With increasing inhibitory control and task difficulty, additional frontal and parietal fc was recruited, and long-range connections established. Insights into early development and refinement of inhibitory control could provide essential information for the support in normal development as well as for the diagnosis and treatment of neurodevelopmental disorders with EF and inhibition difficulties, such as autism spectrum disorder.

\section{Full Text}

Due to technical limitations, full-text HTML conversion of this manuscript could not be completed. However, the latest manuscript can be downloaded and accessed as a PDF.

\section{Table}

Table 1. Participant demographics

\begin{tabular}{lccc}
\hline & $2-3$ year-olds & $3-4$ year-olds & 5 year-olds \\
\hline Number (Boys/ Girls) & $11(8 / 3)$ & $16(9 / 7)$ & $11(6 / 5)$ \\
Age at scan & $27.36(5.61)$ & $48.56(6.54)$ & $67.73(2.10)$ \\
Inhibition score & $6.75(4.35)$ & $13.29(4.03)$ & $15.25(1.14)$ \\
Average balls & $1.02(0.20)$ & $1.13(0.16)$ & $0.66(0.14)$ \\
Average dogs & $1.17(0.21)$ & $1.10(0.17)$ & $0.87(0.10)$ \\
SSI & $0.02(0.26)$ & $-0.13(0.22)$ & $0.07(0.16)$ \\
MSI & $-0.34(0.39)$ & $-0.53(0.49)$ & $-0.73(0.39)$ \\
\hline
\end{tabular}

Mean participant demographics with standard deviations in brackets and age at scan is in months. No information for average balls clicked was acquired for 3 participants in the 2-3 year-olds, 11 for the 3-4 year-olds, and 8 for the 5 year-olds. 
Figures

\section{$\underline{\text { Successful Inhibition Score }}$}
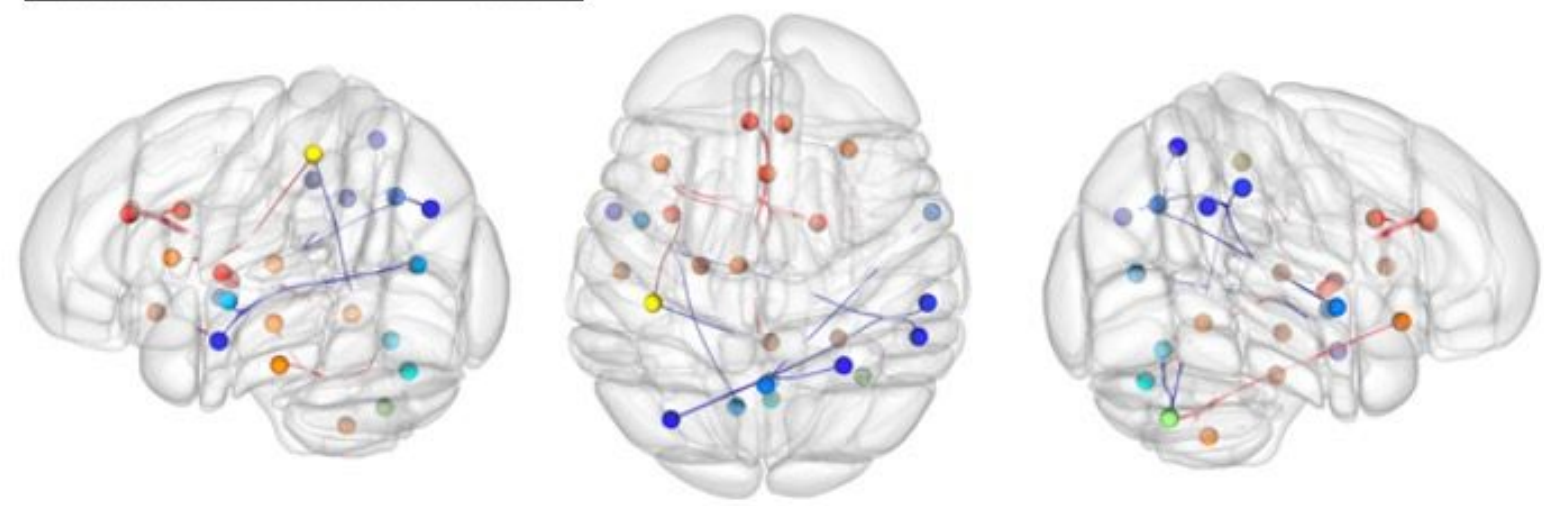

\section{Successful Inhibition Score $2-3<3-4$ years}
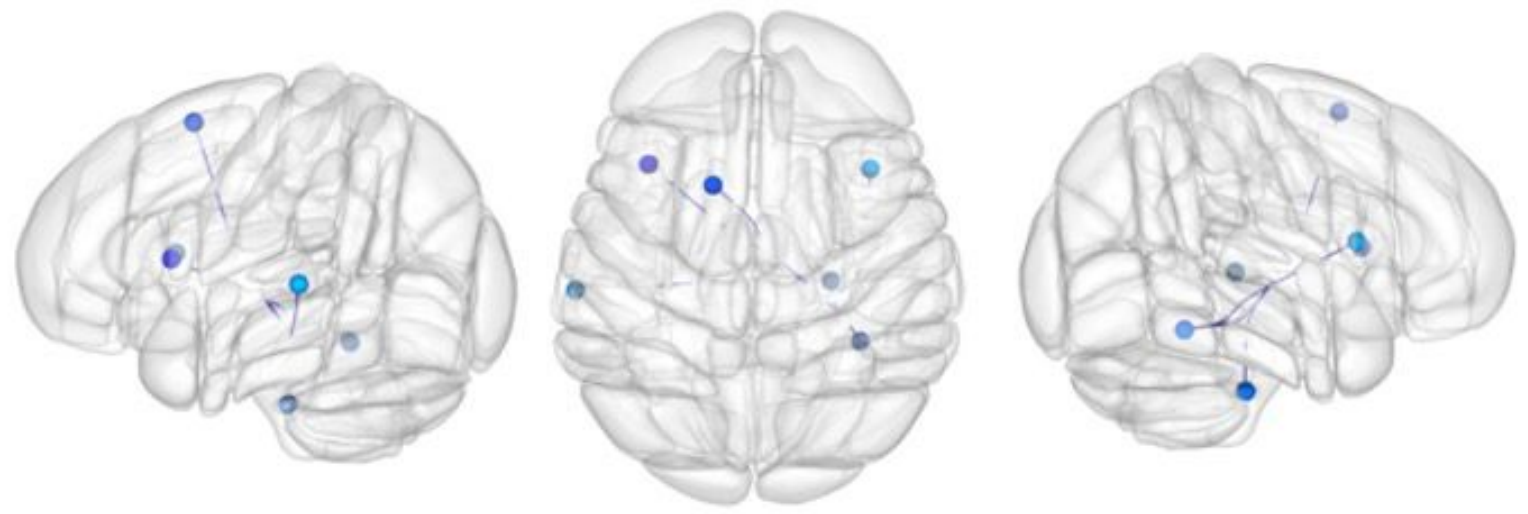

\section{Successful Inhibition Score $2-3<5$ years}
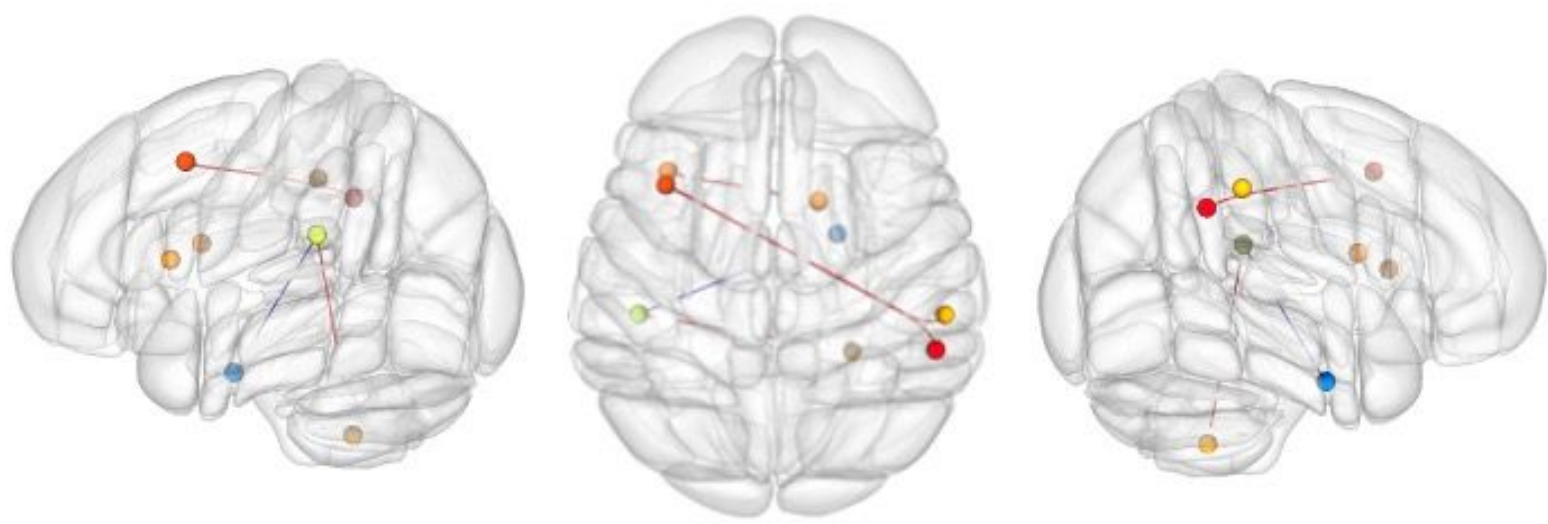

Figure 1

A caption was not provided with this version 


\section{$\underline{\text { Non-Competitive Inhibition }}$}
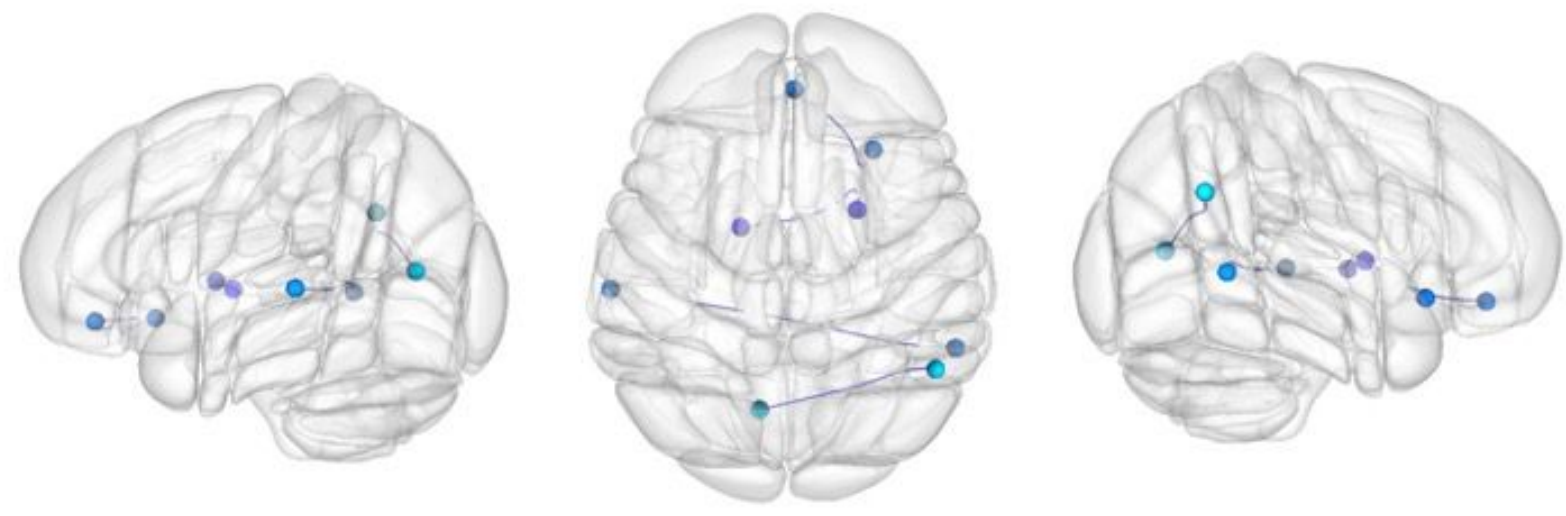

Non-Competitive Inhibition $2-3<3-4$ years
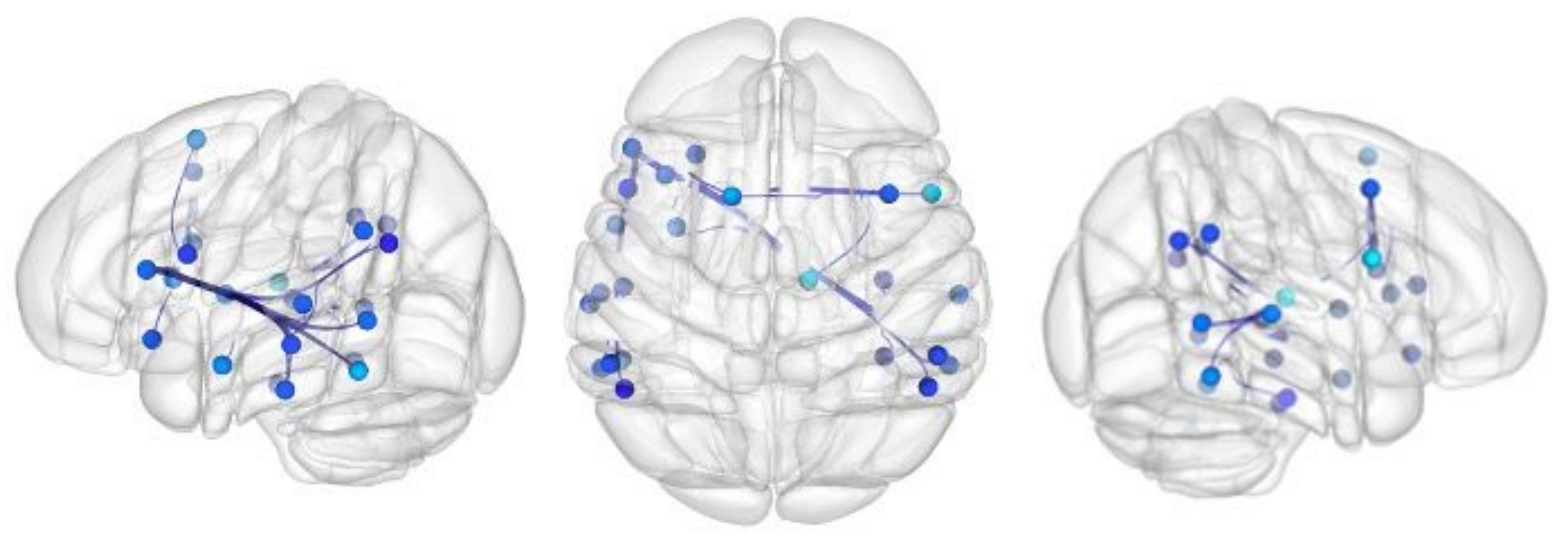

Non-Competitive Inhibition $2-3<5$ years
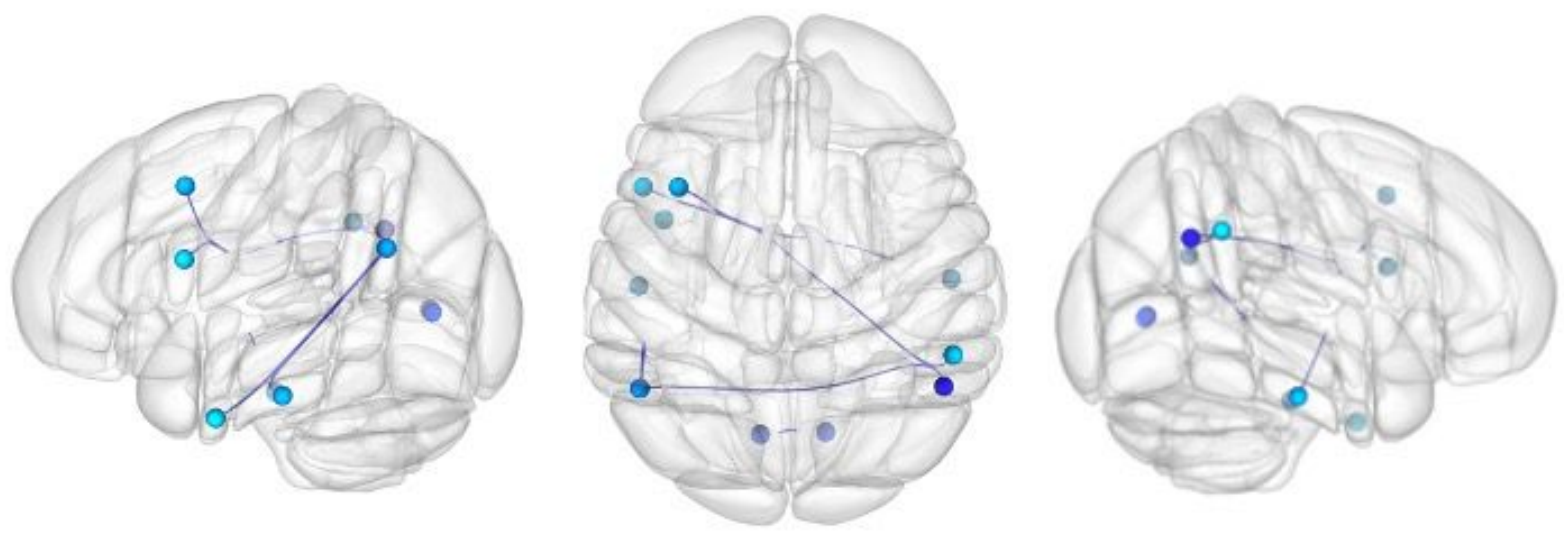

Figure 2

A caption was not provided with this version 


\section{Competitive Inhibition}
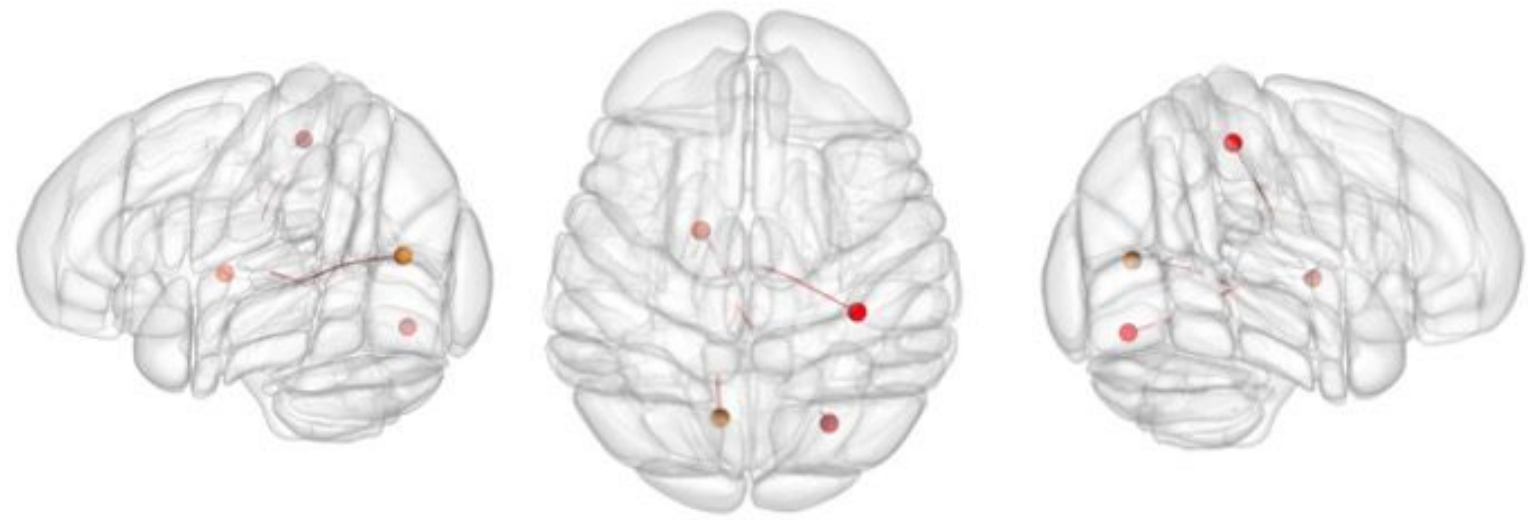

\section{Competitive Inhibition $2-3<3-4$ years}
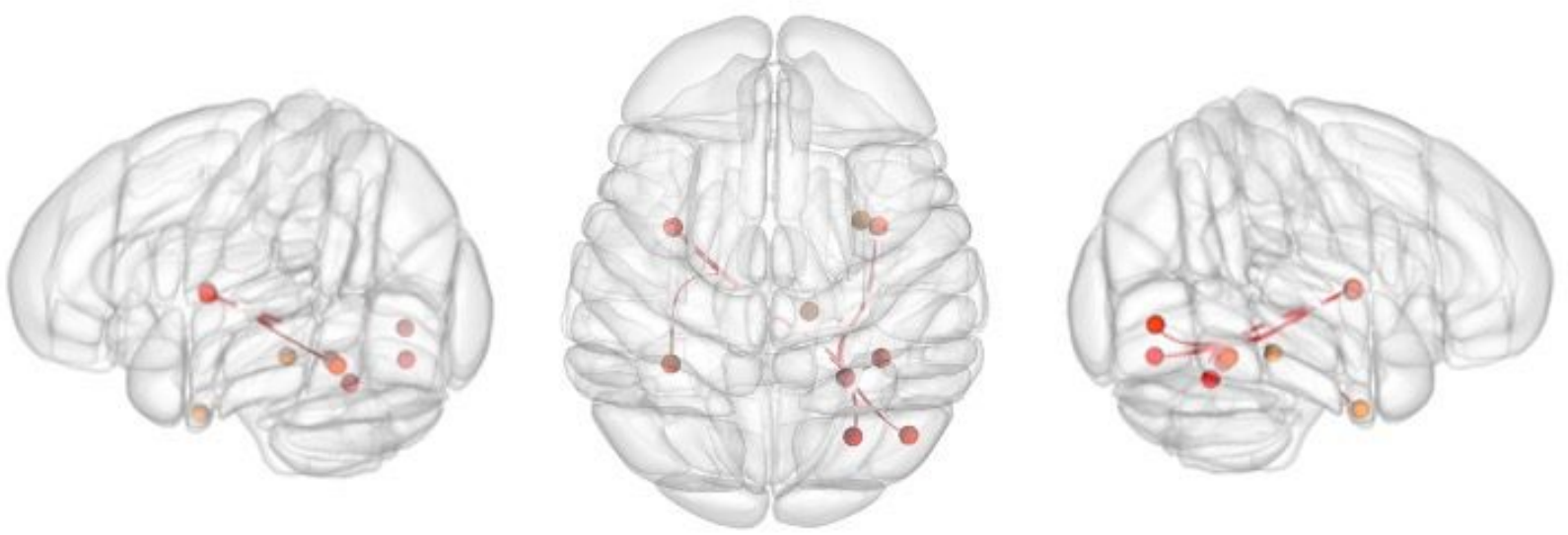

\section{Competitive Inhibition $2-3<5$ years}
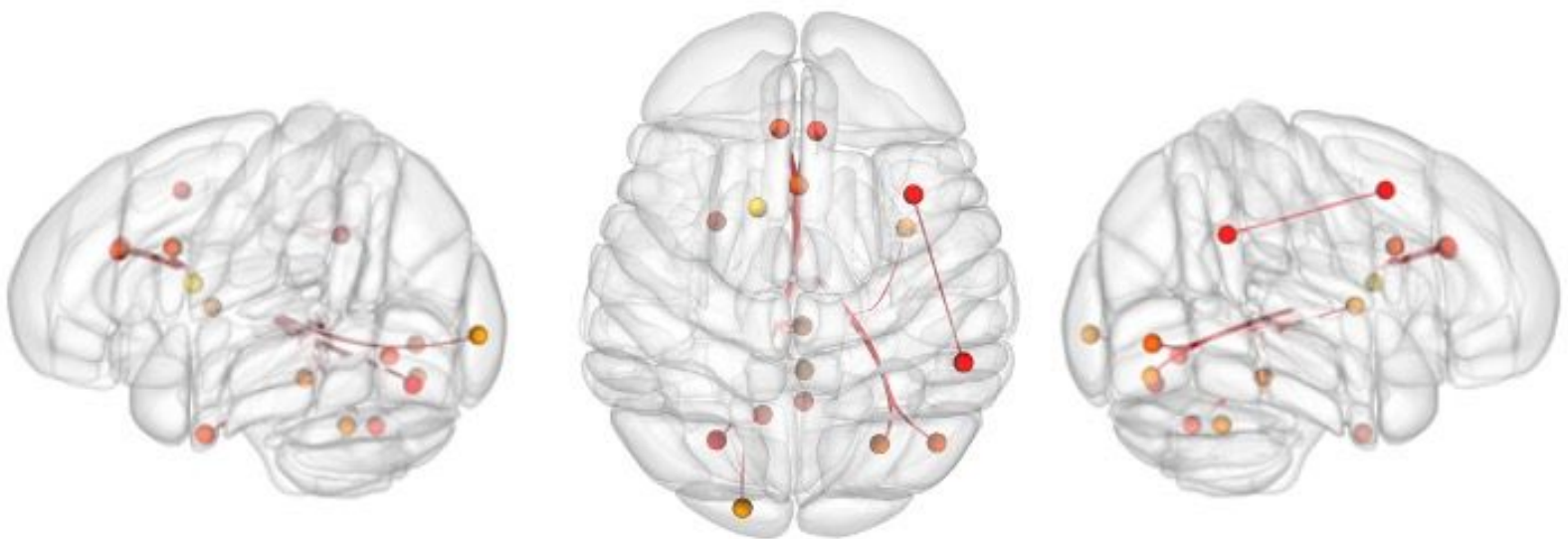

Figure 3

A caption was not provided with this version

\section{Supplementary Files}

This is a list of supplementary files associated with this preprint. Click to download. 
- TableS1.pdf

Page 6/6 